\title{
Recensão: Carlos Nogueira, Resposta a Italo Calvino. Clássicos da Literatura, Porto, Livraria Lello, 2018.
}

\section{José Eduardo Reis}

UTAD - ILC

No ensaio com o título afirmativo "Porquê ler os Clássicos", datado de 1981 e publicado em livro dez anos depois com o mesmo título, porém sob a forma interrogativa, o escritor italiano, ensaísta e consultor literário Italo Calvino (1923-1985) enuncia - com o humor adequado a atenuar a gravitas das grandes questões - catorze possíveis definições assertivas do que é um texto clássico.

No livro Resposta a Italo Calvino, datado de 2018, com o subtítulo Clássicos de Literatura, o crítico literário português, autor de livros infantojuvenis e professor de literatura Carlos Nogueira afere da validade dessas definições em quinze ensaios críticos de extensão variada sobre autores e textos constituintes de um campo da literatura, usualmente arredado dos processos de canonização, e que tem como destinatários um público leitor infantojuvenil.

A primeira nota de recensão crítica a Resposta a Italo Calvino que merece ser explicitada é a que decorre da ousada, mas fundamentada, posição teórica e metodológica enunciada na introdução por C. Nogueira de redefinir a ideia de clássico literário - e, nessa medida, em se propor alargar a aplicação do conceito de cânone literário à literatura infantojuvenil e, até mesmo, à literatura oral tradicional. Essa proposta de redefinição não 
tem em vista desafiar a legitimidade de posições fundadas em depurados e consagrados critérios estéticos e culturais - porém sujeitas a revisão e debate - de críticos escritores, como Harold Bloom no seu Cânone Ocidental (1994), ou de escritores que também são críticos, como Vladimir Nabokov nas suas Aulas de Literatura (1980) sobre Austen, Dickens, Flaubert, Joyce, Kafka, Proust, Stevenson. O critério principal utilizado por C. Nogueira para atribuir o estatuto de clássico a obras literárias intencionalmente concebidas para crianças e adolescentes leitores, e que justifica, aliás, o subtítulo do livro em apreço, é o que se revê na definição nona dada por Italo Calvino: “O nosso clássico é o que não pode ser-nos indiferente e que nos seve para nos definirmos a nós mesmos em relação e se calhar até em contraste com ele" (11). De facto, C. Nogueira não elide a função tutelar que determinadas obras literárias desempenharam no processo de formação da sua própria identidade profissional, cívica, intelectual, cultural, e o modo como tais obras, independentemente da sua categorização genológica ou da sua conformação a variáveis horizontes de receção, se prestam a integrar a sua biblioteca pessoal e a se constituírem em objeto de leitura analítica. Neste sentido, o ensaio introdutório opera no conjunto deste livro como um texto com caráter de manifesto contendo os princípios orientadores da prática hermenêutica de C. Nogueira aplicada à poética da palavra, por vezes também à poética da imagem enquanto suporte ou complemento ilustrativo do verbo intencionalmente articulado para desencadear o espanto da experiência da leitura inaugural - aquela que desempenha uma função de revelação na e de iniciação à complexidade do mundo junto das consciências em formação das crianças e dos jovens. Assumindo o seu interesse enquanto crítico-ensaísta e investigador-pedagogo por todas as modalidades do discurso literário - o que pode ser atestado pelo conteúdo dos seus ensaios sobre autores da literatura portuguesa reunidos no volume São feitas de palavras as palavras (2017) -, C. Nogueira recorre a uma outra definição dada por Italo Calvino, a décima primeira, do que é um clássico para, a partir dela, legitimar as suas incursões ensaísticas no universo literário infantojuvenil. E se de facto um clássico é, de acordo com o autor italiano, "uma obra que provoca incessantemente uma vaga de discursos críticos sobre si, mas que continuamente se livra deles”, torna-se então compreensível que se elaborem exegeses literárias com os seguintes títulos: “De Gil Vicente 
a Fernando Pessoa: os clássicos na literatura para a infância e a juventude"; "Os contos dos irmãos Grimm: história, teoria, receção"; "Heidi, de Johanna Spryl: novela plural”; "Peter Pan ou história de cada um de nós". Se o primeiro dos títulos problematiza os méritos e as limitações estéticas das 24 adaptações feitas por autores contemporâneos de textos clássicos da literatura portuguesa, os três seguintes relevam, na variedade dos seus objetos de análise, sucessivamente, (i) os processos de simbolização de fundo arquetípico veiculados por contos populares germânicos, (ii) a projeção universal e televisiva de uma narrativa tardo oitocentista, Heidi, circunscrita à representação de particularidades da cultura rural e de montanha da Suíça, (iii) a invenção quer de personagens de fantasia, Peter Pan e Sininho, em cujo perfil e ação de conjunto se descortinam crises humanas de crescimento psicológico e controversos papéis de género, quer um mundo maravilhoso, a "Terra do Nunca", lugar de contraponto a uma desencantada e mecanizada sociedade anglo saxónica do início do século XX. A sequência destes primeiros quatro ensaios, como aliás a disposição dos outros onze, denotam uma evidente preocupação estrutural na organização do volume: a um texto crítico focalizado na adaptação do cânone literário português justapõem-se três textos sobre obras da literatura universal, seguidos de outros seis sobre a obra de autores nacionais, a que se sucedem os últimos seis de orientação temática. Como denominador comum da composição destes quinze ensaios entrevê-se, também, o exercício de uma prática de análise literária assumidamente comparatista, fundada na convicção do seu autor de que "o capital simbólico adquirido através da leitura é construtor de um ambiente não só nacional mas também internacional mais democrático, pluralista, dinâmico" (p. 65).

A atenção dada por C. Nogueira à função didática, na sua múltipla aceção - estética, ética, cívica, cultural - da literatura infantojuvenil é, justamente, uma segunda nota a salientar no conjunto dos ensaios de Resposta a Calvino. Se, por exemplo, o texto "A poesia de receção infantil e juvenil em Alexandre O’Neil" chama a atenção das qualidades estéticas dos versos eufónicos e irónicos daquele poeta passíveis de serem apropriados para fins de aprendizagem da leitura literária da poesia, ou se no ensaio "Do Conto Popular e da Lenda (do ciclo do diabo) à literatura para crianças e jovens" é realçada a figura estruturante da 
ironia na construção do cómico enquanto dispositivo retórico utilizado na composição de contos narrativos e romances em verso populares, já os ensaios dedicados à obra de Emília de Sousa Costa, de Álvaro de Magalhães e de António Mota, sem perder de vista a análise da literariedade das suas correspondentes escritas, ressaltam problemáticas com implicações ideológicas, éticas e cívicas de candente atualidade - como as que dizem respeito, respetivamente, ao direitos das mulheres, da natureza e dos animais. Subjacente à declinação desta multidimensional vocação didática da literatura radica uma fundada confiança de C. Nogueira na modelização tendencialmente construtiva, se não mesmo virtuosa, que a literariedade pode operar nas consciências infantis e juvenis despertando-as para a complexidade do mundo e para a desafiadora e indeterminada busca de sentidos para a vida. São múltiplas, explícitas ou correlacionadas as referências feitas, devidamente contextualizadas no devir da exposição dos argumentos e juízos críticos, ao valor gnómico da literatura (e.g. p. 129, p.212, p.247, p.269, p.270, p.281, p. 304, p.331, p.342, p.345, p.352). Nessas referências podem-se identificar três ideias nucleares sobre a função educativa e formadora, se não mesmo catalisadora de indagações existenciais, associadas ao ato performativo da leitura: (i) a iniciática-existencial, no que essa ideia designa de acesso a mundos representados imaginária e verbalmente - "Por experiência da Palavra entenda-se [...] o corpo do texto que se vive intelectual e fisicamente através de uma materialidade significante e de significados em que o leitor é herdeiro e intérprete de um espaço ontológico original" (342); (ii) a consciente-problematizante, pelo que de ambíguo comporta a ideia da perceção de um mundo-palco, irredutível à rígida conformação dicotómica das categorias metafísicas do bem e do mal - “[N]os leitores em formação [há que incutir] um pressuposto fundamental: é verdade que há valores supremos na base da formação do ser humano, mas não é menos certo que as duas linhas de orientação [do bem e do mal] com frequência se tocam, confundem e impugnam, tornando difícil ou impossível, nas múltiplas especificações contextuais, a distinção objetiva e inequívoca entre os dois campos. Na sondagem das relações humanas assim organizada percebe-se como o mundo é uma imparável comédia trágica onde o ser humano oscila entre a abjeção e a grandeza" (58); (iii) a ideia mediadora-divulgadora da literariedade escrita mas também transcrita da 
memória da tradição oral: "a sala de aula, a biblioteca e o auditório da escola podem e devem tornar-se cada vez mais num sucedâneo legítimo dos momentos em que, na nossa sociedade tradicional, o ato narrativo era um ritual de celebração da palavra e da coesão social" (371).

A terceira nota a destacar a Resposta a Italo Calvino é a que incide sobre os argumentos críticos e juízos interpretativos decorrentes da conceção plural e redimensionada do que C. Nogueira designa por "conhecimento humanístico" (20). Atento às limitações antropocêntricas de um Humanismo que terá excluído do seu horizonte intelectual e axiológico a atenção devida ao fecundo e variegado universo vital extra humano, C. Nogueira demonstra os valores de perenidade e atualidade inscritos na noção de clássico literário quando analisa passagens das narrativas $A$ Maior Flor do Mundo e $O$ Lagarto de José Saramago, dos Contos da Mata dos Medos de José Magalhães, bem como o motivo da árvore na literatura infantil e juvenil à luz da ecocrítica - uma modalidade dos estudos literários pós-modernos orientada para a análise das correlações da semiose literária com o meio ambiente. É certamente à luz desta noção distendida do "conhecimento humanístico" e do modo pluridisciplinar com que fundamenta as suas leituras que se compreende que C. Nogueira não elida no seu trabalho hermenêutico nenhum clássico motivo literário, como o da morte (ensaio 13) - convertido em tabu social pela ideologia assética do descarte e pela consciência alienada do princípio da realidade; ou que não ignore a importância dos dispositivos retóricos da ironia e da sátira na propulsão do riso e do humor e na construção do juízo moral e de gosto (ensaio 15). A relevância que reiteradamente o autor confere à função poética da linguagem na formação da autonomia identitária e na vontade de agir cívica e politicamente, não o impede porém de invocar justificadamente a lição lúcida e de advertência de George Steiner sobre as trágicas distorções e perversões a que a cultura literária pode estar exposta quando manipulada para fins ideologicamente sórdidos e anti-humanos (vide, ensaios 8 e 13).

A leitura integral ou discretamente segmentada de Resposta a Calvino revela, portanto, uma alargada consciência do valor de conhecimento cultural e existencial da literatura, sem deixar de se apresentar devidamente escorada, quando o exame de 
pormenor assim o justifica, num proficiente uso de categorias narratológicas e num competente controlo funcional de técnicas de análise textual. A título de exemplo da competência demonstrada da close reading do autor, veja-se a seguinte passagem relativa à análise de um fragmento textual do livro A Biblioteca do Avô, de Maria Rosário Pedreira: "Há não raramente, uma precipitação muito expressiva da linguagem que se organiza à volta de um operador de pontuação muito funcional: o ponto e vírgula, que permite a escansão da frase e do pensamento sem quebrar a elegância do excurso ponderado e alargado" (357). Nos seus exercícios analíticos, C. Nogueira, tomando em consideração um destinatário menos especializado, chega mesmo a praticar o gesto pedagógico a que a sua condição de professor certamente o conduz, quando, por exemplo, explica que "o discurso iterativo" é aquele em que se conta "uma vez o que aconteceu várias vezes de modo idêntico" (291).

Em suma, Resposta a Italo Calvino, não contém uma mas várias respostas sobre o poliédrico conceito de clássico tal como este é declinado pelo escritor italiano. Respostas, porém, não assertivas, mas esclarecidas por uma extensa bibliografia de fundamentação e motivadas por aquele júbilo pedagógico que o patrono do prémio literário atribuído recentemente a este livro, Jacinto do Prado Coelho - aliás nele pertinentemente citado (351) -, considerava ser inerente à disciplina do ensino da literatura, a "mais formativa" da consciência humana, por ser mobilizadora de qualidades cognitivas e estéticas fundamentais: "[s]aber idiomático, experiência prática e vital, sensibilidade, gosto, capacidade de ver, fantasia, espírito crítico." (apud Nogueira 351).

É sob o signo desse saber convertido em discurso crítico que se podem ler os quinze ensaios de C. Nogueira, todos eles reverberando estas suas declarações de princípio: (i) "Penso e escrevo sobre obras que se me impõem como mundos integrais, como representações e (re)construções da vida e do cosmos, como reflexos ativos do (in)consciente individual e coletivo e da (des)construção da História e da Cultura; (ii) [l]eio (e escrevo) em nome não de uma ideia ou de um ideal de estabilidade do texto literário, mas antes em nome da sua natureza instável e problematizadora, irredutível a quaisquer tentativas teóricas e críticas de explicação final e definitiva" (11-12). É, portanto, na interseção destas duas coordenadas que se pode divisar a génese da composição de 
Resposta a Italo Calvino, resposta que, pelo âmbito e qualidade da sua formulação plural e abertura de possibilidades críticas e explicativas, se arrisca a devir um clássico em língua portuguesa da hermenêutica da literatura infantojuvenil. 